\title{
The Impact of Match Location and Players' Physical and Technical Activities on Winning in the German Bundesliga
}

\author{
Marek Konefał ${ }^{1}$, Paweł Chmura ${ }^{2 *}$, Antonio Tessitore ${ }^{3}$, Tomasz Melcer ${ }^{4}$, \\ Edward Kowalczuk ${ }^{5}$, Jan Chmura ${ }^{1}$ and Marcin Andrzejewski ${ }^{6}$
}

\begin{abstract}
1 Department of Biological and Motor Sport Bases, University School of Physical Education in Wrocław, Wrocław, Poland, ${ }^{2}$ Department of Team Sport Games, University School of Physical Education in Wroctaw, Wroclaw, Poland, ${ }^{3}$ Department of Movement, Human and Health Sciences, University of Rome "Foro Italico", Rome, Italy, ${ }^{4}$ Department of Biomedical Engineering, Faculty of Fundamental Problems of Technology, Wroctaw University of Science and Technology, Wroctaw, Poland, ${ }^{5}$ Football Club Hannover 96, Hanover, Germany, ${ }^{6}$ Department of Methodology of Recreation, Poznań University School of Physical Education, Poznań, Poland
\end{abstract}

\section{OPEN ACCESS}

Edited by: Goran Vuckovic,

University of Ljubljana, Slovenia

Reviewed by:

Nuno Mateus,

Universidade de Trás-os-Montes e

Alto Douro, Portugal

Miguel-Angel Gomez-Ruano, Polytechnic University of Madrid,

Spain

${ }^{*}$ Correspondence: Pawet Chmura

pawel.chmura@awf.wroc.pl

Specialty section:

This article was submitted to Movement Science and Sport

Psychology,

a section of the journa

Frontiers in Psychology

Received: 26 March 2020 Accepted: 24 June 2020

Published: 23 July 2020

Citation:

Konefał M, Chmura P, Tessitore A, Melcer T, Kowalczuk E, Chmura J and

Andrzejewski M (2020) The Impact of Match Location and Players' Physical and Technical Activities on Winning in the German Bundesliga.

Front. Psychol. 11:1748

doi: 10.3389/fpsyg.2020.01748
This study aimed to examine whether the physical and technical activities of soccer players and match locations can be associated with higher or lower odds of winning matches whose outcome can be described as "close." The study comprised 7972 individual observations of German Bundesliga players during the 2014/2015 ( $n=2794$ ), $2015 / 2016$ ( $n=2494)$, and $2016 / 2017(n=2684)$ seasons. A selection of "close matches" was made, which were defined as those in which the difference in numbers of scored goals was $\leq 1$. Players' five pitch positions were considered: central defenders, fullbacks, central midfielders, wide midfielders, and forwards. Data on 12 physical and 10 technical activities performed by players during matches as well as on match location were retrieved from the Impire AG (Germany) match analysis system. The study results show that the odds of winning at home are different for each playing position: from $41.99 \%$ for wide midfielders to $91.34 \%$ for central midfielders. Another conclusion was that one of the key components of the predictive model for forwards is the percentage of overall distance covered at speeds $>24 \mathrm{~km} / \mathrm{h}$ (7.99\%), which is a variable with an increasing trend. The proposed model predicts that each $1 \%$ increase in this variable will theoretically be associated with a $4.08 \%$ raise of the odds of winning in further seasons. The presented statistical model may be used by trainers to identify players' physical and technical activities and contextual variables that may significantly affect the match outcome. In addition, it can help to determine the individual training load related to the player's position on the pitch.

Keywords: match analysis, elite football, high intensity, seasons, close matches

\section{INTRODUCTION}

Notational analysis plays a very important role in all sport games, particularly in soccer (Carling et al., 2009; Sarmento et al., 2014). Consequently, match analysis studies can provide useful information for coaches, who need significant, relevant, and easily gathered feedback to be successfully applied in training and competitive matches (Hughes and Franks, 2004; 
Wright et al., 2013). Today, technologically advanced systems are commonly used for data gathering (Castellano et al., 2014) based on the state-of-the-art algorithms along with video-recording technology to supply data on the physical (motion analysis) and technical and tactical (notational analysis) performance of soccer players (Bradley et al., 2013; Konefał et al., 2019a) with regard to their playing positions (Andrzejewski et al., 2018) and contextual variables (Chmura et al., 2017b; Gai et al., 2019; Oliva-Lozano et al., 2020).

During a soccer match, players are engaged in a number of multidirectional physical and technical activities (Krustrup et al., 2005; Wallace and Norton, 2014); however, relevant research on soccer shows that players' technical activities can be better predictors of success than their physical activities (Castellano et al., 2012; Carling, 2013; Di Salvo et al., 2013; Hoppe et al., 2015; Moalla et al., 2017). Among the many technical variables used in soccer match analysis, the most important are considered to be shots, passes, and one-on-one plays (Lago-Penas and Lago-Ballesteros, 2011; Castellano et al., 2012; Liu et al., 2015, 2016; Szwarc et al., 2017). Their high effectiveness is correlated with the match outcome (Shafizadeh et al., 2013; Link and de Lorenzo, 2016; Konefał et al., 2018). The achievement of players' high tactical and technical levels is not possible without players' appropriate levels of physical activity (Mackenzie and Cushion, 2013), whose main measurements include total distance covered, distance covered at high intensity, number of performed sprints, mean running speed, and peak running speed (Andrzejewski et al., 2018; Chmura et al., 2018). A study of Bundesliga players revealed that the highest odds of winning a match $(31.7 \%)$ occur when wide midfielders increase their distance covered at above $24 \mathrm{~km} / \mathrm{h}$ by $0.1 \mathrm{~km}$. Likewise, for fullbacks, increasing the number of sprints will improve the odds of winning a match by $8.6 \%$ (Konefał et al., 2019a).

However, even if the multiple physical and technical variables are regarded as individual aspects of a match, a reductionist approach to them and their separate analyses cannot offer a full reflection of the complexity of all characteristics of a soccer game (Mackenzie and Cushion, 2013). On the one hand, when more detailed consideration is given to the various playing positions, it can be noted that, during the match, the central midfielders perform a higher number of passes and are characterized by the highest passing accuracy, and the forwards perform the highest numbers of shots and shots on target (Bradley et al., 2013). Likewise, the effectiveness of a game played by fullbacks and wide midfielders is associated with the distance covered at high intensity as well as with the number of performed sprints (Andrzejewski et al., 2018; Chmura et al., 2018). In essence, this means that improving the team's success requires a higher level of physical activity from players on some pitch positions and enhanced technical activity from players in others (Di Salvo et al., 2013). On the other hand, these analyses should not be separated from the contextual variables, such as match outcome (Rumpf et al., 2017) and match location, which are also highly correlated with each other (Lago-Penas et al., 2016). Pollard and Pollard (2005) analyzed more than 400,000 matches over the period of 1876-2003 to identify a home-advantage trend in soccer and other team sports games. Therefore, the observed changes in players' activities in subsequent seasons are an important factor (Barnes et al., 2014). An interesting analysis of the World Cup Finals between 1966 and 2010 showed that every single variable considered changed significantly over time (Wallace and Norton, 2014). Bush et al. (2015) also demonstrated that the overall numbers of passes increased by $40 \%$ over seven consecutive seasons of the English Premier League.

In addition, researchers indicate a number of other determinants of players' activity during a match, including quality of opposition (Bilek and Ulas, 2019), team and opposition ability (Redwood-Brown et al., 2019), team formation (Aquino et al., 2020), match status (Gonzalez Rodenas et al., 2019), players' age and experience (Lorenzo-Martínez et al., 2019), and climate conditions (Coker et al., 2020). However, during a soccer match, players experience all these factors simultaneously, which is why modern studies focus on multifactorial analyses, using advanced statistical methods (Moura et al., 2014). Taylor et al. (2008) used logistic regression to develop a model to assess the frequency of on-the-ball technical activities performed by a professional British soccer team as a function of match location and quality of opposition in relation to match outcome. Aquino et al. (2020) noted that matches played at home or against "weaker" opponents presented greater running demands and that match outcome demonstrated influence only for running performance; matches in which the reference team won resulted in higher values than in matches lost. Bilek and Ulas (2019) used the decision tree identifying scoring first as the most influential on match outcome in each decision tree, and the impact of match location on the match outcome varied according to the quality of the opponent. Multivariate analyses (adjusted logistic multilevel models) by Gonzalez Rodenas et al. (2019) showed how playing at home and against high-ranked opponents involved a higher likelihood of achieving offensive penetration although no associations were found in terms of creation of scoring opportunities. There is a significant relationship between match location, quality of opposition, and other contextual variables affecting the physical and technical activities of soccer players.

An interesting point of further exploration of this issue may be the combination into one multivariate analysis of match locations with players' pitch positions and the match outcome. We know that each playing position displays different physical and technical activities, and this depends on the match outcome (Sarmento et al., 2014). It can be assumed that such differences in physical and technical activity will also occur when such an important contextual factor as match location is considered in the statistical model. It may be particularly interesting to find out how the home or away games affect players in different pitch positions. In addition, researchers have demonstrated that a specific winning and losing margin should be employed to identify the closeness of a game score and that only close matches can be seen as representative of the best performance between two opposing teams (Gomez et al., 2014; Liu et al., 2016).

Considering the abovementioned information, the present study aimed to examine whether different levels of players' physical and technical activities and match location were associated with higher or lower odds of winning or losing close matches of the German Bundesliga. 


\section{MATERIALS AND METHODS}

\section{Participants}

The study material consisted of observations $(n=556)$ from Bundesliga soccer players playing in three seasons from $2014 / 2015$ to $2016 / 2017$. Of all studied players, 228 played one season, 167 played two seasons, and 161 played three seasons. The number of studied players in subsequent seasons was as follows: 2014/2015 $(n=349), 2015 / 2016(n=344)$, and $2016 / 2017(n=352)$. The study material comprised 13,032 individual observations of activities of outfield players (goalkeepers were excluded). Only players who played whole matches were selected for the study.

In total, 918 matches were assigned to one of two categories: (i) close matches (7972 match observations) during 2014/2015 ( $n=2794), 2015 / 2016(n=2494)$, and 2016/2017 $(n=2684)$ in which the difference in match score was up to 1 goal $(\leq 1)$ and (ii) unbalanced games (5060 match observations) in which the difference in match score was two or more goals $(\geq 2)$ (Liu et al., 2016). Further analyses were confined to close matches. Moreover, five pitch positions of players were considered (Bradley et al., 2013; Andrzejewski et al., 2018; Chmura et al., 2018): central defenders (CD, 2210 match observations), fullbacks (FB, 1691 match observations), central midfielders (CM, 1963 match observations), wide midfielders (WM, 1159 match observations), and forwards (F, 949 match observations).

The study conformed with the Declaration of Helsinki and was approved by the local Ethics Committee (No. 339/15). The study protocol was also approved by the local board of ethics.

\section{Procedures}

The notational analysis of 918 played matches was carried with the use of the Impire AG match analysis system (Germany) (Tiedemann et al., 2011) with a recording frequency of $25 \mathrm{~Hz}$. Each player's movement was recorded by two cameras (Link and Weber, 2017). The system utilizes state-of-the-art algorithms and 2-D and 3-D video-recording technology, allowing for detailed motion analysis of entire soccer matches. The major advantages of vision-based systems are their high update rate corresponding to the camera-frame rate and the fact that the players and the ball are tracked simultaneously. The validity and reliability of this system have been described in detail elsewhere (Liu et al., 2013).

Performance-related activities were divided into two groups: (1) physical variables: total distance $[\mathrm{km}]$ covered during the match; distance $[\mathrm{km}]$ covered at speeds below or above $14.4 \mathrm{~km} \cdot \mathrm{h}^{-1}$ (below or above the anaerobic threshold); distance $[\mathrm{km}]$ and the percentage of distance covered at intensity ranges $<11 \mathrm{~km} \cdot \mathrm{h}^{-1}, 11-14 \mathrm{~km} \cdot \mathrm{h}^{-1}, 14-17 \mathrm{~km} \cdot \mathrm{h}^{-1}, 17-21 \mathrm{~km} \cdot \mathrm{h}^{-1}, 21-$ $24 \mathrm{~km} \cdot \mathrm{h}^{-1}$, and $>24 \mathrm{~km} \cdot \mathrm{h}^{-1}$; numbers of performed sprints during a match (runs with a speed $>22.68 \mathrm{~km} \cdot \mathrm{h}^{-1}$ and at least $1 \mathrm{~s}$ in duration); numbers of efforts at high intensity (above $18 \mathrm{~km} \cdot \mathrm{h}^{-1}$ ); mean running speed $\left[\mathrm{km} \cdot \mathrm{h}^{-1}\right]$; and peak running speed $\left[\mathrm{km} \cdot \mathrm{h}^{-1}\right.$ ] (Andrzejewski et al., 2018; Chmura et al., 2018) and (2) technical variables: numbers of shots, i.e., attempts to score a goal made with any (legal) part of the body, either on or off target; numbers of ball touches; numbers of passes, i.e., intentionally played balls from one player to another; pass accuracy [\%], i.e., successful passes as a proportion of total passes; numbers of crosses, i.e., any balls sent into the opposition team's area from a wide position; numbers of oneon-one plays (game actions in which two players from different teams compete for the ball, and the action is always assigned to both participant players); and number and percentage of oneon-one plays won (Konefał et al., 2019a). Additionally, the study also considered the contextual variable of match location, i.e., whether a team was playing at its own ground $(1=$ Home $)$ or at its opponent's (0 = Away) (Gonzalez Rodenas et al., 2019). Complete definitions of physical and technical variables are available at the DFL | Definitionskatalog Offizielle Spieldaten Bundesliga website ${ }^{1}$.

For each variable of physical or technical activity performed by a player in a given match, an extra variable was set measuring the change in the coefficient in three consecutive seasons. These additional variables were defined as an interaction term between the original variable and the season's sequential number, i.e., 0 for the 2014/2015 season, 1 for the 2015/2016 season, and 2 for the 2016/2017 season (Tibshirani, 2011).

\section{Statistical Analysis}

Statistical analysis was carried out using the STATISTICA ver. 13.1 (StatSoft Inc., United States) software package and the glmnet $\mathrm{R}$ package for regression analysis (Tibshirani, 2011). The selection of physical and technical activities for the predictive models was made using the lasso method (Tibshirani, 2011), i.e., a method for variable selection by regularization, applicable to a large class of linear models. The lasso penalizes models by adding an $\mathrm{L}^{1}$ norm of the model parameters to the cost function. The $\mathrm{L}^{1}$ norm favors models with many coefficients set to zero, effectively performing feature selection by suppressing variables that have a small influence on the target variable, weak predictors correlated to stronger variables, and, in this particular case, variables for which it was not possible to decide on the direction of the effect on match outcome on the basis of the analyzed data set (Konefał et al., 2019a). The lasso method is preferred to the practice of choosing variables by reference to $p$-values of statistical tests or methods, such as forward feature selection or backward feature elimination, due to the fact that variable selection is an inherent part of model construction, and hence, parameter estimates as well as various model test statistics are more reliable (Tibshirani, 2011; Harrell, 2015). Logistic regression with the lasso penalty was applied with the match outcome as the dichotomous variable: $1=$ win, $0=$ loss or draw. The model was estimated using the least-angle regression method (Efron et al., 2014) with the permutation test for model components also being applied as suggested by Tibshirani (2011). The level of statistical significance for the permutation test was set at $\alpha=0.05$. It should be noted here that the use of the chisquare or Wald tests would result in biased confidence interval estimates when applied directly to the results obtained using the lasso method (Tibshirani, 2011).

\footnotetext{
${ }^{1}$ https://s.bundesliga.com/assets/doc/10000/2189_original.pdf
} 


\section{RESULTS}

The descriptive statistics for the examined variables concerning players' pitch positions in close matches are shown in Table 1.

In close matches, as regards to forwards, the statistically significant model $\left(\mathrm{chi}^{2} p\right.$-value $\left.<0.040\right)$ revealed statistical significance in relation to distance covered at speeds below $14.4 \mathrm{~km} \cdot \mathrm{h}^{-1}(p<0.001)$, percentage distance covered at speeds $>24 \mathrm{~km} \cdot \mathrm{h}^{-1}(p<0.026)$, percentage distance covered at speeds $>24 \mathrm{~km} \cdot \mathrm{h}^{-1}$ - seasons $(p<0.004)$, number of sprints $(p<0.014)$, total number of shots $(p<0.001)$, total number of shots - seasons $(p<0.012)$, the number of one-on-one plays $(p<0.044)$, and playing at home $(p<0.001)$ (Table 2$)$.

As far as the wide midfielders were concerned $\left(\mathrm{chi}^{2}\right.$ $p$-value $<0.001)$, the statistically significant variables were total distance covered $(p<0.012)$, distance covered at speeds $>24 \mathrm{~km} \cdot \mathrm{h}^{-1}(p<0.031)$, numbers of passes $(p<0.005)$, numbers of crosses $(p<0.025)$, and playing at home $(p<0.001)$. In line with the estimated model $\left(\mathrm{chi}^{2} p\right.$-value $\left.<0.001\right)$, the statistically significant variables for central midfielders were, in turn, total distance covered $(p<0.001)$, distance covered at speeds below $11 \mathrm{~km} \cdot \mathrm{h}^{-1}(p<0.001)$, percentage distance covered at $14-17 \mathrm{~km} \cdot \mathrm{h}^{-1}(p<0.001)$, mean running speed $(p<0.001)$, numbers of passes $(p<0.040)$, numbers of crosses $(p<0.003)$, and playing at home $(p<0.001)$. For fullbacks (chi ${ }^{2} p$-value $\left.<0.001\right)$, the statistically significant variables were distances covered at speeds below $11 \mathrm{~km} \cdot \mathrm{h}^{-1}(p<0.007)$, numbers of crosses $(p<0.027)$, and playing at home $(p<0.001)$. In the estimated model $\left(\mathrm{chi}^{2} p\right.$-value $\left.<0.001\right)$ only playing at home $(p<0.001)$ was statistically significant for central defenders (Table 2).

\section{DISCUSSION}

This study aimed to examine whether different levels of soccer players' physical and technical activities and match location were associated with higher or lower odds of winning or losing close matches in the German Bundesliga. Our main findings show that match location is a contextual variable present in the estimated models for all pitch positions, having a positive effect on the odds of a close match being won. The importance of playing at home in soccer has been emphasized in many previous studies (LagoPenas et al., 2010; Lago-Penas and Lago-Ballesteros, 2011; Liu et al., 2016), and although the significance of home advantage has declined steadily from around $70 \%$ in 1890 to around 60\% today, it remains clear that match location continues to exert a major influence on the match outcome (Pollard and Pollard, 2005).

TABLE 1 | Physical and technical activities of players in different pitch positions in close games (means and SD).

\begin{tabular}{|c|c|c|c|c|c|}
\hline \multirow[t]{2}{*}{ Variables } & \multicolumn{5}{|c|}{ Close games $(\leq 1)$} \\
\hline & $\mathbf{F}$ & WM & CM & FB & CD \\
\hline Total distance covered [km] & $10.70 \pm 0.90$ & $11.19 \pm 0.71^{*}$ & $11.55 \pm 0.70^{\star}$ & $10.72 \pm 0.60$ & $10.03 \pm 0.61$ \\
\hline Distance covered below 11 km/h [km] & $6.29 \pm 0.30^{*}$ & $6.28 \pm 0.31$ & $6.20 \pm 0.30^{*}$ & $6.24 \pm 0.32^{*}$ & $6.36 \pm 0.31$ \\
\hline Distance covered at 11-14 km/h [\%] & $15.65 \pm 2.30$ & $16.47 \pm 1.89$ & $19.07 \pm 2.10^{\star}$ & $16.57 \pm 1.63$ & $16.49 \pm 1.99$ \\
\hline Distance covered below 14.4 km/h [km] & $8.16 \pm 0.50^{\star}$ & $8.33 \pm 0.43$ & $8.66 \pm 0.40$ & $8.21 \pm 0.41$ & $8.19 \pm 0.42$ \\
\hline Distance covered at 14-17 km/h [\%] & $10.25 \pm 1.8$ & $11.20 \pm 1.59$ & $13.19 \pm 2.10^{*}$ & $10.76 \pm 1.45$ & $9.58 \pm 1.59$ \\
\hline Distance covered at speeds $>24 \mathrm{~km} / \mathrm{h}[\mathrm{km}]$ & $0.33 \pm 0.10$ & $0.37 \pm 0.13^{\star}$ & $0.21 \pm 0.10$ & $0.31 \pm 0.11$ & $0.16 \pm 0.08$ \\
\hline Distance covered at speeds > 24 km/h [\%] & $3.06 \pm 1.20^{\star}$ & $3.30 \pm 1.15$ & $1.80 \pm 0.90$ & $2.87 \pm 1.01$ & $1.61 \pm 0.74$ \\
\hline Distance covered at speeds $>24 \mathrm{~km} / \mathrm{h}$ - seasons [\%] & $3.06 \pm 1.20^{\star}$ & $3.30 \pm 1.15$ & $1.80 \pm 0.90$ & $2.87 \pm 1.01$ & $1.61 \pm 0.74$ \\
\hline Sprints [number] & $24.44 \pm 7.70^{\star}$ & $26.36 \pm 7.40$ & $17.00 \pm 6.60^{\star}$ & $22.33 \pm 6.37$ & $12.97 \pm 4.88$ \\
\hline Sprints - seasons [number] & $24.44 \pm 7.70$ & $26.36 \pm 7.40$ & $17.00 \pm 6.60^{\star}$ & $22.33 \pm 6.37$ & $12.97 \pm 4.88$ \\
\hline Efforts at high intensity above 18 km/h [number] & $42.47 \pm 10.90$ & $45.45 \pm 9.96$ & $47.48 \pm 12.30^{\star}$ & $40.03 \pm 8.59$ & $30.33 \pm 7.64$ \\
\hline Peak running speed [km/h] & $31.49 \pm 1.60^{\star}$ & $31.82 \pm 1.41$ & $30.20 \pm 1.60^{\star}$ & $31.46 \pm 1.31$ & $30.58 \pm 1.64$ \\
\hline Mean running speed [km/h] & $6.81 \pm 0.50$ & $7.11 \pm 0.47$ & $7.34 \pm 0.50^{*}$ & $6.82 \pm 0.40$ & $6.38 \pm 0.40$ \\
\hline Total shots [number] & $2.54 \pm 1.69^{\star}$ & $1.81 \pm 1.55$ & $1.15 \pm 1.27^{\star}$ & $0.54 \pm 0.81$ & $0.58 \pm 0.83$ \\
\hline Total shots - seasons [number] & $2.54 \pm 1.69^{\star}$ & $1.81 \pm 1.55$ & $1.15 \pm 1.27$ & $0.54 \pm 0.81$ & $0.58 \pm 0.83$ \\
\hline Passes [number] & $23.39 \pm 9.79$ & $32.17 \pm 12.77^{\star}$ & $47.07 \pm 20.38^{\star}$ & $39.26 \pm 15.59$ & $49.18 \pm 24.53$ \\
\hline Pass accuracy [\%] & $66.76 \pm 12.43^{\star}$ & $69.99 \pm 11.91$ & $76.45 \pm 10.92$ & $71.29 \pm 12.13$ & $78.55 \pm 11.88$ \\
\hline Crosses [number] & $0.89 \pm 1.44$ & $2.16 \pm 2.22^{*}$ & $0.69 \pm 1.33^{\star}$ & $1.92 \pm 1.85^{\star}$ & $0.10 \pm 0.49$ \\
\hline Crosses - seasons [number] & $0.89 \pm 1.44^{\star}$ & $2.16 \pm 2.22$ & $0.69 \pm 1.33$ & $1.92 \pm 1.85$ & $0.10 \pm 0.49$ \\
\hline One-on-one plays [number] & $25.10 \pm 8.84^{*}$ & $22.71 \pm 7.85$ & $22.17 \pm 7.40$ & $17.95 \pm 6.09$ & $15.23 \pm 5.55$ \\
\hline One-on-one plays won [number] & $10.99 \pm 4.61$ & $10.72 \pm 4.48$ & $11.23 \pm 4.52^{*}$ & $9.96 \pm 4.02$ & $9.19 \pm 3.97$ \\
\hline One-on-one plays won - seasons [number] & $10.99 \pm 4.61$ & $10.72 \pm 4.48$ & $11.23 \pm 4.52^{*}$ & $9.96 \pm 4.02$ & $9.19 \pm 3.97$ \\
\hline Percentage of one-on-one plays won & $43.92 \pm 10.78$ & $47.37 \pm 11.91$ & $50.66 \pm 12.06^{\star}$ & $55.42 \pm 12.62$ & $60.17 \pm 14.46$ \\
\hline Playing at home & $0.001^{*}$ & $0.001^{*}$ & $0.001^{*}$ & $0.001^{*}$ & $0.001^{*}$ \\
\hline
\end{tabular}

*Variables selected for the model with the use of the lasso method due to their predictive power. Pitch positions: forwards (F), wide midfielders (WM), central midfielders (CM), fullbacks (FB), and central defenders (CD). 
TABLE 2 | Relationships between selected variables and match outcomes among elite German soccer players.

\begin{tabular}{|c|c|c|c|c|c|}
\hline \multirow[t]{2}{*}{ Parameters } & \multicolumn{5}{|c|}{ Close games $(\leq 1)$} \\
\hline & $\mathbf{F}$ & WM & CM & FB & CD \\
\hline $\begin{array}{l}\text { Total distance covered (increase by } \\
0.1 \mathrm{~km} \text { ) }\end{array}$ & & 55.94 & $+^{*}$ & & \\
\hline $\begin{array}{l}\text { Distance covered below } 11 \mathrm{~km} / \mathrm{h} \\
\text { (increase by } 0.1 \mathrm{~km} \text { ) }\end{array}$ & & & $+^{\star}$ & $+^{*}$ & \\
\hline $\begin{array}{l}\text { Distance covered below } 14.4 \mathrm{~km} / \mathrm{h} \\
\text { (increase by } 0.1 \mathrm{~km} \text { ) }\end{array}$ & $+^{*}$ & & & & \\
\hline $\begin{array}{l}\text { Distance covered at } 14-17 \mathrm{~km} / \mathrm{h} \\
\text { (increase by } 1 \% \text { ) }\end{array}$ & & & 8.81 & & \\
\hline $\begin{array}{l}\text { Distance covered at speeds }>24 \mathrm{~km} / \mathrm{h} \\
\text { (increase by } 0.1 \mathrm{~km} \text { ) }\end{array}$ & & 60.71 & & & \\
\hline $\begin{array}{l}\text { Distance covered at speeds }>24 \mathrm{~km} / \mathrm{h} \\
\text { (increase by } 1 \% \text { ) }\end{array}$ & 7.99 & & & & \\
\hline $\begin{array}{l}\text { Distance covered at speeds }>24 \mathrm{~km} / \mathrm{h} \\
\text { - seasons (increase by 1\%) }\end{array}$ & 4.08 & & & & \\
\hline Number of sprints (unit increase) & 1.41 & & & & \\
\hline $\begin{array}{l}\text { Mean running speed (increase by } \\
0.1 \mathrm{~km} / \mathrm{h} \text { ) }\end{array}$ & & & $-*$ & & \\
\hline Total number of shots (unit increase) & 11.44 & & & & \\
\hline $\begin{array}{l}\text { Total number of shots - seasons (unit } \\
\text { increase) }\end{array}$ & 2.72 & & & & \\
\hline Number of passes (unit increase) & & 0.41 & -0.41 & & \\
\hline Number of crosses (unit increase) & & -0.54 & -9.16 & -0.28 & \\
\hline $\begin{array}{l}\text { Number of one-on-one plays (unit } \\
\text { increase) }\end{array}$ & 0.88 & & & & \\
\hline Playing at home & 51.75 & 41.99 & 91.34 & 49.34 & 59.93 \\
\hline
\end{tabular}

Results marked with an asterisk ("**) were identified by visual inspection as unreliable in terms of values for the coefficient. These results have a very large confidence interval. This means that even though the model selected the variable as a contributor to the match outcome, more-precise estimate cannot be attained, but it can merely point out the direction of the variable's effect as helpful (positive) or harmful (negative) for the match outcome.

The mean value of playing at home, irrespective of the five playing positions analyzed in our study, was 59\%. It is a similar percentage to that observed by Pollard and Gómez (2014), who drew on data from the Spanish Professional League to determine a mean value for home advantage equal to $62 \%$. However, our study is the first to demonstrate in a more detailed way how the odds of winning at home are different for each playing position with the range from $42 \%$ for wide midfielders to $91 \%$ for central midfielders. Furthermore, the $60 \%$ noted for central defenders represented the only component of the model relating to this position. It can be argued that central midfielders, due to the position-specific technical and tactical requirements for directing the match, are more affected by the game at home than wide midfielders and defenders. This may be due to the fact that central midfielders are characterized by longer ball possession and higher numbers of attacking behaviors (e.g., shots, dribbles, and ball touches) when playing at home (Konefał et al., 2019b). This result clearly shows that match location should be taken into account by coaching staffs in their analyses for the entire team (Liu et al., 2016) as well as individual players in different pitch positions.
However, despite the high home advantage noted in our study, the impact of match location itself should be assessed with caution. If the opponent is presenting a lower level of quality, a home match does not affect the odds of winning, but it increases the probability of a draw and reduces the probability of a loss. However, if the opponent is stronger, playing at home provides an extra 14\% chance of winning (Bilek and Ulas, 2019). Other respondents indicate that playing at home and playing against high-ranked opponents increases the effectiveness of the offense but does not affect the goal-scoring opportunities (Gonzalez Rodenas et al., 2019). Other studies, however, do not confirm this "finding" (Almeida et al., 2014) and show an increase in offensive rates. It follows that even multivariate analyses may not capture the high level of complexity (e.g., Almeida et al., 2014; Gonzalez Rodenas et al., 2019) that soccer styles represent, where constant interaction between team members, opponents, and context constraints creates dynamic and interdependent situations that are different and unique in each match. A very interesting example of these complex relationships is the study showing the decision tree for games in which the quality of the team is inferior to the opponent. In such a match, without taking into account any variable, it can be concluded that the team is likely to lose the match with a probability of 0.59 . However, if the team scores the first goal, it will roughly triple its chance to win. Moreover, if the team is the host, its probability of winning increases to 0.62 . In addition, if the team manages to keep the percentage of possession of the ball above $44 \%$, it is very likely that the team will win the game with a probability of 0.89 (Bilek and Ulas, 2019).

The present study shows that, as far as forwards are concerned, the odds of winning are higher in matches in which a player covers a greater percentage of distance at speeds $>24 \mathrm{~km} \cdot \mathrm{h}^{-1}$ and performs a higher number of sprints. These results are in line with the findings by Andrzejewski et al. (2018) and Chmura et al. (2018), who showed that the fact that the forwards were able to perform more sprints and runs of high intensity was crucial to the match outcome. Moreover, Andrzejewski et al. (2018) also stressed that, in soccer, high-intensity activities occur more often in offensive play. The findings of the present study indicate that the predictive model for forwards stressed not only the greater percentage of the distance covered at speeds higher than $24 \mathrm{~km} \cdot \mathrm{h}^{-1}$ and also its significant improvement over the seasons. The model predicts that a value for $1 \%$ higher will be associated with a steady (4.08\%) increase in the odds of winning in subsequent seasons. Previous studies also revealed a $30-50 \%$ increase in the distances covered at high intensity or by sprinting by players of the English Premier League in the last decade. However, our research emphasizes the increase in forwards' play intensity as an ongoing process, which is essential for the improvement of the odds of winning (Bradley et al., 2013). In fact, this ability has a particular relevance for forwards because most goals are scored in the wake of dynamic actions taken by these players (Njororai, 2013). Furthermore, shots represent, in turn, a further key variable to be taken into account in developing a model for forwards. In this regard, our findings show that when a forward takes single shots more frequently during a match, the odds of winning the game increase by $11 \%$. In turn, in further 
seasons, an increased chance of winning was associated with an increased frequency of this technical activity (in subsequent seasons, one extra shot increased the odds of winning by $2.72 \%$ ). The importance of shots is confirmed by many studies showing that differences between match status (winning or losing) in the case of professional teams are mainly attributed to the numbers of shots at goal as well as the effectiveness thereof with the task of performing shots mainly assigned to forwards (Lago-Penas et al., 2010; Castellano et al., 2012; Liu et al., 2015). On the other hand, Barnes et al. (2014) did not observe any changes in the numbers of shots taken over seven seasons of the English Premier League. However, the present study was not confined only to forwards. In our sample, the forwards took $2.54 \pm 1.69$ shots on average in each match. For comparison, during the Euro 2012 championship, the mean number of shots for all matches and for all pitch positions was $16.83 \pm 7.60$ (Shafizadeh et al., 2013). Also during the Euro 2016 championship, one shot was taken every 7 min on average (Konefał et al., 2018). This could be explained by the fact that, in games characterized by smaller differences in the numbers of goals, far greater significance is assigned to numbers of shots taken by forwards. Moreover, shots are part of a model that makes associations between one whole entity and other variables of physical activity (distance covered at speeds greater than $24 \mathrm{~km} \cdot \mathrm{h}^{-1}$, number of sprints), or tactical activity (one-on-one plays) (Liu et al., 2015; Szwarc et al., 2017).

The estimated models for wide midfielders highlighted total distance covered (55.94\%), distance covered at a speed $>24 \mathrm{~km} \cdot \mathrm{h}^{-1}(60.71 \%)$, and number of passes $(0.41 \%)$ as relevant variables that could positively influence the match outcome. In present-day soccer, wide midfielders are players who, during a match, above all others, very often cover the longest distance at high intensity (Lago-Penas et al., 2016). Interestingly, a predictive model developed by Konefał et al. (2019a) using data from the 2014/2015 Bundesliga season also indicated the importance of wide midfielders' distance covered at speeds $>24 \mathrm{~km} \cdot \mathrm{h}^{-1}$, albeit with the odds of winning amounting to $31.7 \%$ and the number of passes to $3.3 \%$.

The present study is confined to the analysis of close matches and not all matches. This can account for the noted lesser significance of technical activities in the case of wide midfielders and an associated greater relevance of their physical activities manifested by their coverage of long distances as well as distances at very high intensity during a match. Nowadays, in soccer close matches, wide midfielders in possession of the ball often take part in dynamic offensive actions while following losses of the ball by covering long distances and returning to defensive tasks (Goncalves et al., 2017; Baptista et al., 2018). This is also an indication for soccer clubs recruiting wide midfielders to select those characterized by more "explosive" abilities and a capacity to engage in frequently repeated high-intensity efforts (Bush et al., 2015; Chmura et al., 2018).

As far as central midfielders are concerned, the variables related to the increase of odds of match winning included total distance covered and distance covered at speeds below $11 \mathrm{~km} \cdot \mathrm{h}^{-1}$. The importance of these variables was emphasized by Chmura et al. (2017a), who showed that the 2014 World Cup winning team covered a significantly greater total distance per match compared to the other teams. However, despite a positive relationship between these variables and match outcome, the model does not supply precise information on the rate of change. This may be a reflection of the major input of other external factors, such as differences in playing and coaching styles.

As regards central midfielders, the model considered the percentage of distance covered at $14-17 \mathrm{~km} \cdot \mathrm{h}^{-1}$, whose increase was associated with an $8.81 \%$ change in the odds of winning as well as with the negative influence of mean running speed. It may be that central midfielders' movement on the field at such an intensity favors closer observation and perception of the situation on the pitch, thus ensuring a more effective implementation of match tasks (Chmura and Nazar, 2010). The analysis of close matches in the present study shows that the transfer of the ball to wide midfielders and forwards increases the dynamics of the game and leads to a greater number of shots being taken. However, it is also important to note that the impact of numbers of passes and crosses by central midfielders on the match outcome is negative. Bush et al. (2015) found that over the English Premier League 2006/7-2012/13 seasons central midfielders were able to achieve a $50 \%$ increase in the number of performed passes. In turn, Bradley et al. (2013) showed that it was central midfielders who were responsible for most passes. The different results in our study regarding the activity of central midfielders as well as fullbacks may point to differences in playing styles in particular national soccer leagues or to a new trend of changes in the style of play among modern soccer teams. The latter may be based on the idea that, on average, it passes from the midfield to the attacking area that proves most effective (Rein et al., 2017) and that the ratio of goals from shots is better for "direct play" than for "possession play" (Hughes and Franks, 2005). This way of soccer play could be observed in successive matches of the 2018 World Cup in Russia.

A limitation of the present study is that the statistical model should include more contextual-related variables influencing match running performance and behaviors of professional players, such as level of opposition (top, middle, bottom) and match status (win, draw, lose). Also styles of play were not considered in the study, and thus, no associations with winning or KPIs could have been examined. In addition, the present study focuses on one specific league (the Bundesliga), and therefore, the data obtained should be considered with some caution. Also adding more numbers of seasons to the database and $k$-means clustering will allow for more accurate modeling and predictions of what actions should be performed by soccer players to raise the odds of winning in further seasons. In further studies, the data should be normalized by each individual player's contribution to his team during each match. Last, future research should also consider environmental conditions, team tactics, and players' age/experience.

\section{CONCLUSION}

An important new finding of the present study is that playing at home is the most significant determinant of match outcome for Bundesliga professional soccer players in all pitch positions. However, the odds of winning at home were found to vary 
with pitch position, being the lowest among wide midfielders and the highest among central midfielders. The results of close matches over three Bundesliga seasons were determined to a greater extent by the activity of offensive players than defensive players. Statistical models predicting the odds of winning a match revealed the statistical significance of distance covered at very high intensity, number of sprints, and total distance covered as well as the total numbers of shots and numbers of one-onone plays for forwards and wide midfielders. The application of an additional variable to measure the change of coefficient for all studied variables in consecutive seasons pointed to the great significance of the evolution of the game, percentage distance covered at speeds greater than $24 \mathrm{~km} \cdot \mathrm{h}^{-1}$, and total number of shots among the forwards.

In comparison with analyses of all matches, the present study, which was confined to close matches only, revealed a declining significance of technical activities and increasing significance of physical activities among wide midfielders. This is manifested by players covering longer distances during matches as well as longer distances at higher intensities.

\section{PRACTICAL APPLICATION}

The results of the present study provide practical information that can be effectively used in physical, tactical, and technical training. First, the study shows that match location is a contextual variable present in the estimated models for all pitch positions, having a positive effect on the odds of winning a close match. Second, the results of our study show that, to increase the odds of match winning, the soccer training for forwards and wide midfielders should focus more on high- and very highintensity efforts. The offensive players must demonstrate a high level of aerobic capacity, tolerance to increasing fatigue, and anaerobic capacity. Having such potential can prevent the decrease in the players' ability to repeat sprints. This can have a positive impact on the efficiency of technical activities, especially more shots on goal as this variable will play an increasingly important role with each subsequent season. Therefore, the

\section{REFERENCES}

Almeida, C., Ferreira, A., and Volossovitch, A. (2014). Effects of match location. match status and quality of opposition on regaining possession in UEFA champions league. J. Hum. Kinet. 41, 203-214. doi: 10.2478/hukin-20140048

Andrzejewski, M., Chmura, P., Konefał, M., Kowalczuk, E., and Chmura, J. (2018). Match outcome and sprinting activities in match play by elite German soccer players. J. Sports Med. Phys. Fitness 58, 785-792.

Aquino, R., Carling, C., Vieira, L. H. P., Martins, G., Jabor, G., Machado, J., et al. (2020). Influence of situational variables, team formation, and playing position on match running performance and social network analysis in brazilian professional soccer players. J. Strength Cond. Res. 34, 808-817. doi: 10.1519/jsc. 0000000000002725

Baptista, I., Johansen, D., Seabra, A., and Pettersen, S. A. (2018). Position specific player load during match-play in a professional football club. PLoS One 13:e0198115. doi: 10.1371/journal.pone.0198115

Barnes, C., Archer, D. T., Hogg, B., Bush, M., and Bradley, P. S. (2014). The evolution of physical and technical performance parameters in the English above recommendations should be considered when selecting offensive players.

The presented statistical model may be used by coaching staffs to identify players' physical and technical activities and contextual variables that may significantly affect the match outcome. In addition, it can help to determine individual training loads related to the player's position on the pitch.

\section{DATA AVAILABILITY STATEMENT}

The raw data supporting the conclusions of this article will be made available by the authors, without undue reservation, to any qualified researcher.

\section{ETHICS STATEMENT}

The studies involving human participants were reviewed and approved by the Local Board of Ethics. This study maintains the anonymity of the players following data protection laws, and was conducted in compliance with the Declaration of Helsinki. The patients/participants provided their written informed consent to participate in this study.

\section{AUTHOR CONTRIBUTIONS}

MK, PC, JC, and MA conceptualized the study and contributed to the study methodology and writing (original draft). MK, $\mathrm{PC}$, and EK undertook the data curation and investigation. MK and TM were responsible for the formal analysis and visualization and contributed to the software. JC contributed to the funding acquisition. MK, AT, and JC undertook the project administration and responsible for the supervision. MK, $\mathrm{EK}$, and JC contributed to the resources. MK, PC, AT, JC, and MA contributed to the validation and writing (review and editing). All authors contributed to the article and approved the submitted version.

Premier League. Int. J. Sports Med. 35, 1095-1100. doi: 10.1055/s-00341375695

Bilek, G., and Ulas, E. (2019). Predicting match outcome according to the quality of opponent in the English premier league using situational variables and team performance indicators. Int. J. Perform. Anal. Sport 19, 930-941. doi: 10.1080/ 24748668.2019.1684773

Bradley, P. S., Lago-Penas, C., Rey, E., and Gomez Diaz, A. (2013). The effect of high and low percentage ball possession on physical and technical profiles in English FA Premier League soccer matches. J. Sports Sci. 31, 1261-1270. doi: 10.1080/02640414.2013. 786185

Bush, M., Barnes, C., Archer, D. T., Hogg, B., and Bradley, P. S. (2015). Evolution of match performance parameters for various playing positions in the English premier league. Hum. Mov. Sci. 39, 1-11. doi: 10.1016/j.humov.2014.10.003

Carling, C. (2013). Interpreting physical performance in professional soccer matchplay: should we be more pragmatic in our approach? Sports Med. 43, 655-663. doi: 10.1007/s40279-013-0055-8

Carling, C., Reilly, T., and Williams, A. (2009). Performance Assessment for Field Sports. London: Routledge. 
Castellano, J., Alvarez-Pastor, D., and Bradley, P. S. (2014). Evaluation of research using computerised tracking systems (Amisco and Prozone) to analyse physical performance in elite soccer: a systematic review. Sports Med. 44, 701-712. doi: 10.1007/s40279-014-0144-3

Castellano, J., Casamichana, D., and Lago, C. (2012). The use of match statistics that discriminate between successful and unsuccessful soccer teams. J. Hum. Kinet. 31, 139-147.

Chmura, J., and Nazar, K. (2010). Parallel changes in the onset of blood lactate accumulation (OBLA) and threshold of psychomotor performance deterioration during incremental exercise after training in athletes. Int. J. Psychophysiol. 75, 287-290. doi: 10.1016/j.ijpsycho.2009.12.011

Chmura, P., Andrzejewski, M., Konefał, M., Mroczek, D., Rokita, A., and Chmura, J. (2017a). Analysis of motor activities of professional soccer players during the 2014 World Cup in Brazil. J. Hum. Kinet. 56, 187-195. doi: 10.1515/hukin2017-0036

Chmura, P., Konefał, M., Andrzejewski, M., Kosowski, J., Rokita, A., and Chmura, J. (2017b). Physical activity profile of 2014 FIFA World Cup players, with regard to different ranges of air temperature and relative humidity. Int. J. Biometeorol. 61, 677-684. doi: 10.1007/s00484-016-1245-5

Chmura, P., Konefał, M., Chmura, J., Kowalczuk, E., Zając, T., Rokita, A., et al. (2018). Match outcome and running performance in different intensity ranges among elite soccer players. Biol. Sport 35, 197-203.

Coker, N. A., Wells, A. J., and Gepner, Y. (2020). Effect of heat stress on measures of running performance and heart rate responses during a competitive season in male soccer players. J. Strength Cond. Res. 34, 1141-1149. doi: 10.1519/jsc. 0000000000002441

Di Salvo, V., Pigozzi, F., Gonzalez-Haro, C., Laughlin, M. S., and De Witt, J. K. (2013). Match performance comparison in top English soccer leagues. Int. J. Sports Med. 34, 526-532. doi: 10.1055/s-0032-1327660

Efron, B., Hastie, T., Johnstone, I., and Tibshirani, R. (2014). Least angle regression. Ann. Stat. 32, 407-499.

Gai, Y., Volossovitch, A., Leicht, A. S., and Gómez, M. Á (2019). Technical and physical performances of Chinese super league soccer players differ according to their playing status and position. Int. J. Perform. Anal. Sport 19, 878-892. doi: 10.1080/24748668.2019.1669356

Gomez, M. A., Lago-Penas, C., Viano, J., and Gonzalez-Garcia, I. (2014). Effects of game location, Team quality and final outcome on game-related statistics in professional handball close games. Kinesiology 46, 249-257.

Goncalves, B., Esteves, P., Folgado, H., Ric, A., Torrents, C., and Sampaio, J. (2017). Effects of pitch area-restrictions on tactical behavior, physical, and physiological performances in soccer large-sided games. J. Strength Cond. Res. 31, 2398-2408. doi: $10.1519 /$ jsc. 0000000000001700

Gonzalez Rodenas, J., Aranda, R., Tudela-Desantes, A., Calabuig Moreno, F., Sanjurjo, C. A. C., and Aranda, R. (2019). Effect of match location, team ranking, match status and tactical dimenions on the offensive performance in Spanish 'La Liga'soccer matches. Front. Psychol. 10:2089.

Harrell, F. (2015). Regression Modeling Strategies: With Applications to Linear Models, Logistic and Ordinal Regression, and Survival Analysis. New York: Springer.

Hoppe, M. W., Slomka, M., Baumgart, C., Weber, H., and Freiwald, J. (2015). Match running performance and success across a season in German Bundesliga soccer teams. Int. J. Sports Med. 36, 563-566. doi: 10.1055/s-0034-1398578

Hughes, M., and Franks, I. (2005). Analysis of passing sequences, shots and goals in soccer. J. Sports Sci. 23, 509-514. doi: 10.1080/0264041041000171 6779

Hughes, M. D., and Franks, I. M. (2004). Notational Analysis of Sport: Systems for Better Coaching and Performance. London: E. \& F. N. Spon.

Konefał, M., Chmura, P., Kowalczuk, E., Figueiredo, A. J., Sarmento, H., Rokita, A., et al. (2019a). Modeling of relationships between physical and technical activities and match outcome in elite German soccer players. J. Sports Med. Phys. Fitness 59, 752-759.

Konefał, M., Chmura, P., Zacharko, M., Chmura, J., Rokita, A., and Andrzejewski, M. (2018). Match outcome vs match status and frequency of selected technical activities of soccer players during UEFA Euro 2016. Int. J. Perform. Anal. Sport 18, 568-581. doi: 10.1080/24748668.2018.1501991

Konefał, M., Chmura, P., Zając, T., Chmura, J., Kowalczuk, E., and Andrzejewski, M. (2019b). A new approach to the analysis of pitch-positions in professional soccer. J. Hum. Kinet. 66, 143-153. doi: 10.2478/hukin-2018-0067
Krustrup, P., Mohr, M., Ellingsgaard, H., and Bangsbo, J. (2005). Physical demands during an elite female soccer game: importance of training status. Med. Sci. Sports Exerc. 37, 1242-1248. doi: 10.1249/01.mss.0000170062.73981.94

Lago-Penas, C., Gómez-Ruano, M., Megías-Navarro, D., and Pollard, R. (2016). Home advantage in football: examining the effect of scoring first on match outcome in the five major European leagues. Int. J. Perform. Anal. Sport 16, 411-421. doi: 10.1080/24748668.2016.11868897

Lago-Penas, C., and Lago-Ballesteros, J. (2011). Game location and team quality effects on performance profiles in professional soccer. J. Sports Sci. Med. 10, $465-471$.

Lago-Penas, C., Lago-Ballesteros, J., Dellal, A., and Gomez, M. (2010). Gamerelated statistics that discriminated winning, drawing and losing teams from the Spanish Soccer League. J. Sports Sci. Med. 9, 288-293.

Link, D., and de Lorenzo, M. F. (2016). Seasonal pacing - match importance affects activity in professional soccer. PLoS One 11:e0157127. doi: 10.1371/journal. pone.0157127

Link, D., and Weber, H. (2017). Effect of ambient temperature on pacing in soccer depends on skill level. J. Strength Cond. Res. 31, 1766-1770. doi: 10.1519/jsc. 0000000000001013

Liu, H., Gomez, M. A., Lago-Penas, C., and Sampaio, J. (2015). Match statistics related to winning in the group stage of 2014 Brazil FIFA World Cup. J. Sports Sci. 33, 1205-1213. doi: 10.1080/02640414.2015.1022578

Liu, H., Hopkins, W., Gómez, A. M., and Molinuevo, S. J. (2013). Inter-operator reliability of live football match statistics from OPTA sportsdata. Int. J. Perform. Anal. Sport 13, 803-821. doi: 10.1080/24748668.2013.11868690

Liu, H., Hopkins, W. G., and Gomez, M. A. (2016). Modelling relationships between match events and match outcome in elite football. Eur. J. Sport Sci. 16, 516-525. doi: 10.1080/17461391.2015.1042527

Lorenzo-Martínez, M., Rey, E., and Padrón-Cabo, A. (2019). The effect of age on between-match physical performance variability in professional soccer players. Res. Sports Med. 23, 351-359. doi: 10.1080/15438627.2019.1680985

Mackenzie, R., and Cushion, C. (2013). Performance analysis in football: a critical review and implications for future research. J. Sports Sci. 31, 639-676. doi: 10.1080/02640414.2012.746720

Moalla, W., Fessi, M. S., Makni, E., Dellal, A., Filetti, C., Di Salvo, V., et al. (2017). Association of physical and technical activities with partial match status in a soccer professional team. J. Strength Cond. Res. 32, 1708-1714. doi: 10.1519/ jsc.0000000000002033

Moura, F. A., Martins, L. E. B., and Cunha, S. A. (2014). Analysis of football gamerelated statistics using multivariate techniques. J. Sports Sci. 32, 1881-1887. doi: 10.1080/02640414.2013.853130

Njororai, S. (2013). Analysis of goals scored in the 2010 world cup soccer tournament held in South Africa. J. Phys. Educ. Sport 13, 6-13.

Oliva-Lozano, J. M., Rojas-Valverde, D., Gómez-Carmona, C. D., Fortes, V., and Pino-Ortega, J. (2020). Impact of contextual variables on the representative external load profile of spanish professional soccer match-play: a full season study. Eur. J. Sport Sci. 12, 1-10. doi: 10.1080/17461391.2020.175 1305

Pollard, R., and Gómez, M. A. (2014). Components of home advantage in 157 national soccer leagues worldwide. Int. J. Sport Exerc. Psychol. 12, 218-233. doi: 10.1080/1612197x.2014.888245

Pollard, R., and Pollard, G. (2005). Long-term trends in home advantage in professional team sports in North America and England (1876-2003). J. Sports Sci. 23, 337-350. doi: 10.1080/02640410400021559

Redwood-Brown, A. J., O’Donoghue, P. G., Nevill, A. M., Saward, C., and Sunderland, C. (2019). Effects of playing position, pitch location, opposition ability and team ability on the technical performance of elite soccer players in different score line states. PLoS One 14:e211707. doi: 10.1371/journal.pone. 0211707

Rein, R., Raabe, D., and Memmert, D. (2017). "Which pass is better?" Novel approaches to assess passing effectiveness in elite soccer. Hum. Mov. Sci. 55, 172-181. doi: 10.1016/j.humov.2017.07.010

Rumpf, M. C., Silva, J. R., Hertzog, M., Farooq, A., and Nassis, G. (2017). Technical and physical analysis of the 2014 FIFA World Cup Brazil: winners vs. losers. J. Sports Med. Phys. Fitness 57, 1338-1343.

Sarmento, H., Marcelino, R., Anguera, M. T., Campanico, J., Matos, N., and Leitao, J. C. (2014). Match analysis in football: a systematic review. J. Sports Sci. 32, 1831-1843. doi: 10.1080/02640414.2014.898852 
Shafizadeh, M., Taylor, M., and Penas, C. L. (2013). Performance consistency of international soccer teams in euro 2012: a time series analysis. J. Hum. Kinet. 38, 213-226. doi: 10.2478/hukin-2013-0061

Szwarc, A., Kromke, K., Radzimiński, Ł, and Jastrzębski, Z. (2017). Efficiency of 1-on-1 play situations for high-level soccer players during the World and European championships in relation to position on the pitch and match time. Int. J. Sports Sci. Coa 12, 495-503. doi: 10.1177/174795411771 7890

Taylor, J. B., Mellalieu, S. D., James, N., and Shearer, D. A. (2008). The influence of match location, quality of opposition, and match status on technical performance in professional association football. J. Sports Sci. 26, 885-895. doi: $10.1080 / 02640410701836887$

Tibshirani, R. (2011). Regression shrinkage and selection via the lasso: a retrospective. J. R. Stat. Soc. Ser. B Stat. Methodol. 73, 273-282. doi: 10.1111/ j.1467-9868.2011.00771.x

Tiedemann, T., Francksen, T., and Latacz-Lohmann, U. (2011). Assessing the performance of German Bundesliga football players: a non-parametric metafrontier approach. Cent. Eur. J. Oper. Res. 19, 571-587. doi: 10.1007/ s10100-010-0146-7
Wallace, J. L., and Norton, K. I. (2014). Evolution of World Cup soccer final games 1966-2010: game structure, speed and play patterns. J. Sci. Med. Sport 17, 223-228. doi: 10.1016/j.jsams.2013.03.016

Wright, C., Atkins, S., Jones, B., and Todd, J. (2013). The role of performance analysts within the coaching process: performance analysts survey 'the role of performance analysts in elite football club settings.'. Int. J. Perform. Anal. Sport 13, 240-261. doi: 10.1080/24748668.2013.11868645

Conflict of Interest: The authors declare that the research was conducted in the absence of any commercial or financial relationships that could be construed as a potential conflict of interest.

Copyright (C) 2020 Konefat, Chmura, Tessitore, Melcer, Kowalczuk, Chmura and Andrzejewski. This is an open-access article distributed under the terms of the Creative Commons Attribution License (CC BY). The use, distribution or reproduction in other forums is permitted, provided the original author(s) and the copyright owner(s) are credited and that the original publication in this journal is cited, in accordance with accepted academic practice. No use, distribution or reproduction is permitted which does not comply with these terms. 